\title{
Ecosystem-dependent responses of vegetation coverage on the Tibetan Plateau to climate factors and their lag periods
}

\author{
shuohao cai ${ }^{1}$, Xiaoning Song ${ }^{1}$, Ronghai $\mathrm{Hu}^{1}$, and $\mathrm{Da} \mathrm{Guo}^{1}$ \\ ${ }^{1}$ University of the Chinese Academy of Sciences
}

June 1,2020

\begin{abstract}
The spatial-temporal variation characteristics of vegetation activity and its climate response patterns are of great significance in deepening our understanding of regional vegetation degradation and climate change trends. The re-sponse of vegetation to climate factors varies spatially due to its heterogeneity. Moreover, there may be lag periods before climate factors affect vegetation. In this paper, we studied the responses of vegetation to climate factors at an ecosystem-dependent scale. GIMMS NDVI3g data were collected to indicate vegetation activity. Pure pixels with a single vegetation type were extracted to reduce the influence of the raw NDVI data. Then, a stepwise regression meth-od was adopted to calculate the regression equation for NDVI and meteorological data with the consideration of effect lag times. In the results, the vegetation activity showed an overall increasing trend over the last 31 years, but there was strong spatial heterogeneity. The response of vegetation activity to most climate factors showed a lag, especially the response to precipitation. Generally, there was no correlation between vegetation coverage and precipitation at the start of the growing season. Moreover, for most vegetation, the correlation between vegetation activity and precipita-tion increased to a peak and then decreased during the growing season. In addition, there was no obvious lag period for the effect of the sunshine percentage on vegetation. The lag period of temperature varied on different vegetation type and growth stage. These findings could contribute to a better understanding of the drivers and mechanisms of vegeta-tion degradation on the Tibetan Plateau.
\end{abstract}

\section{KEYWORDS}

NDVI, ecosystem-dependent scale, lag effect, climate factors, the Tibetan Plateau

\begin{abstract}
The spatial-temporal variation characteristics of vegetation activity and its climate response patterns are of great significance in deepening our understanding of regional vegetation degradation and climate change trends. The response of vegetation to climate factors varies spatially due to its heterogeneity. Moreover, there may be lag periods before climate factors affect vegetation. In this paper, we studied the responses of vegetation to climate factors at an ecosystem-dependent scale. GIMMS NDVI3g data were collected to indicate vegetation activity. Pure pixels with a single vegetation type were extracted to reduce the influence of the raw NDVI data. Then, a stepwise regression method was adopted to calculate the regression equation for NDVI and meteorological data with the consideration of effect lag times. In the results, the vegetation activity showed an overall increasing trend over the last 31 years, but there was strong spatial heterogeneity. The response of vegetation activity to most climate factors showed a lag, especially the response to precipitation. Generally, there was no correlation between vegetation coverage and precipitation at the start of the growing season. Moreover, for most vegetation, the correlation between vegetation activity and precipitation increased to a peak and then decreased during the growing season. In addition, there was no obvious lag period for the effect of the sunshine percentage on vegetation. The lag period
\end{abstract}


of temperature varied on different vegetation type and growth stage. These findings could contribute to a better understanding of the drivers and mechanisms of vegetation degradation on the Tibetan Plateau.

\section{1 | INTRODUCTION}

The ecosystem on the Tibetan Plateau is extremely fragile, and its ability to resist disturbance and regenerate is weak (Cui \& Graf, 2009). The temperature of the Tibetan Plateau has been constantly increasing due to global warming, and the rate of warming on the plateau is higher than that in other parts of China (Cui \& Graf, 2009; Piao et al., 2004). The study of the spatial and temporal distribution characteristics of vegetation and its climate response on the Tibetan Plateau is significant for deepening the understanding of trends in the ecological effects of climate change on vegetation degradation.

The impact of climate change on vegetation occurs at different spatial and temporal scales, and it is difficult to meet the requirements for monitoring changes at regional or global scales with traditional monitoring methods (Pang et al., 2017). With its rapid development, remote sensing technology has realized the long-term monitoring of the dynamic changes in vegetation cover in certain regions, which has improved data availability for research on vegetation responses to climate (Potter \& Brooks, 1998). In particular, widely available vegetation index data from the Moderate-Resolution Imaging Spectroradiometer (MODIS) and Advanced Very High Resolution Radiometer (AVHRR) are very useful for the successful assessment, detection, and depiction of landscape conditions and their responses to climate variations at both global and regional scales (Guo et al., 2014).

Although NDVI data are strongly related to plant phenological variables and climatic parameters, these relationships are ecosystem-dependent, and can be highly site-specific (Prasad et al., 2008; Mingguo \& Veroustraete, 2004) and vary widely in different ecosystems, such as soil ecosystems (FARRAR et al., 1994) and vegetation ecosystems (White et al., 1997). At present, most studies have examined the relationship between climate and vegetation at different scales, which reflects the spatial distribution of vegetation activity changes. Due to stratified heterogeneity, considering the property information (i.e., vegetation type, land cover type, etc.) of each pixel is very useful for understanding the mechanisms of the effect of climate on vegetation. Therefore, it is important to study the relationship between vegetation and climate factors at subregional scales. Among the many potential spatial scales for studies, it is most reasonable to explore climatic effects on different vegetation ecosystems (i.e., at the vegetation type scale). The response of different grassland systems to climate change can vary greatly (Li et al., 2018). The same type of vegetation will often have a similar climate environment and similar response mechanisms to climate factors.

For a long time, temperature and water stress have been the primary considerations in studies on climate factors affecting vegetation activity (Wang et al., 2014). As research progresses, an increasing number of climate factors are being taken into account. Sunlight, i.e., solar radiation, provides an energy source for vegetative photosynthesis. On the Tibetan Plateau, sunshine has a more significant impact on vegetation in the southeast region of the plateau (Wang et al., 2014). The lack of radiation observation sites may be the main reason why the influence of radiation is rarely considered in studies, but the sunshine percentage may be a feasible replacement. The relative humidity can reflect the dry and wet conditions of an area to some extent and can have interactive effects with vegetation (Lin et al., 2013). Minimum temperature resistance can be a significant influencing factor on vegetation activity (Prasad et al., 2008; Woodward \& McKee, 1991).

The effect of precipitation on vegetation shows significant lag (Pang et al., 2017). Many studies have been carried out on the lag in the effect of precipitation on vegetation growth, indicating that the lag time of the climate factors that affect vegetation growth varies among different vegetation ecosystems and growth stages (Sivakumar, 1988; DAVENPORT \& NICHOLSON, 1993; Capecchi et al., 2008; Philippon et al., 2005; Martiny et al., 2005). In addition to precipitation, some studies have been conducted on lag effects of other climate factors on vegetation. Piao. (2003) analyzed the monthly average NDVI variation and found that 
NDVI in April or May was significantly correlated with the temperature in February. Wen et al. (2017) analyzed the regional differences in the lag time of effects at the pixel scale, concluding that there was regional heterogeneity in the amount of lag in the effects of both precipitation and temperature. Revealing the lag in the effects of climate factors on vegetation is significant for understanding the ecological mechanisms of vegetation change.

In this study, long-term GIMMS (Global Inventory Modeling and Mapping Studies) NDVI data and the precipitation, average temperature, average minimum temperature, average maximum temperature, relative humidity, sunshine percentage data from the same period were collected to study the spatial and temporal variation patterns of vegetation on the Tibetan Plateau and the ecological mechanisms of the response of vegetation to climate factors from 1985 to 2015 . Based on the 1:1,000,000 vegetation type data for China, ten vegetation domain types and pure pixels for each type of vegetation were selected as the study area to reduce errors due to the coarse spatial resolution of NDVI. Because these climate factors affect vegetation activity in different ways and the relationships among them are also complex, stepwise regression was adopted, which can reduce the effects of collinearity between independent variables to some extent. Moreover, instead of simply using the meteorological data from the same period as the NDVI data, the regression equation for NDVI and meteorological data in the period when vegetation activity was the most strongly correlated with meteorological factors was calculated.

\section{2 | MATERIALS AND METHODS}

\subsection{Study area}

The Tibetan Plateau (Figure 1) extends from the southern edge of the Himalayas to the northern edge of the Kunlun, Altun and Qilian Mountains (26 00 $\sim 39^{\circ} 47^{\prime} \mathrm{N}, 73^{\circ} 19^{\prime \sim} 104^{\circ} 47^{\prime} \mathrm{E}$ ). Its western border is formed by the Pamir Plateau and Karakorum Mountains, and its eastern and northeastern areas are connected with the western Qinling Mountains and the Loess Plateau. The climate of the Tibetan Plateau is generally characterized by strong radiation, high sunshine, low overall temperature, large diurnal temperature differences, distinct dry and wet seasons, a warm and wet climate in the southeast and a dry and cold climate in the northwest, and a decreasing trend of temperature and precipitation from the southeast to the northwest.

\section{2 | Data collection}

\subsection{1 | NDVI Data}

Because the NDVI is directly correlated with vegetation productivity, there are numerous possible applications of this index for ecological purposes (Pettorelli et al., 2005). NDVI data from the AVHRR data set have the advantages of a long time sequence, wide coverage, and high accuracy, which is currently considered one of the best data sets for long-term NDVI analysis.

Since 1994, NDVI data from the AVHRR data set have been made publicly available on the Internet (http://www.noaa.gov). We obtained the third-generation data set recently released by the GIMMS of the National Aeronautics and Space Administration (NASA) from the Internet with a data range from 1985 to 2015. To obtain the monthly NDVI data, the 16-day resolution data were synthesized using the maximum value composites (MVC) method, which can minimize the influence of clouds and the direction of reflection, reduce the effects of the sun angle and shadow, and aerosols and water vapor (HOLBEN, 1986).

\subsection{2 | Climate Data}

Meteorological data were collected from 176 meteorological stations in the administrative region of the Tibetan Plateau. We obtained monthly ground climate data for China from 1985 to 2015 from the China 
Meteorological Data Service Center (CMDC). In this study, six meteorological factors, namely, average precipitation, average temperature, average maximum temperature, average minimum temperature, monthly sunshine percentage and average relative humidity, were taken into account, and these meteorological data were interpolated into raster data with the same spatial resolution as the NDVI data for further correlation analysis.

Moreover, AUNSPLINE and kriging interpolation methods were used to interpolate the meteorological data. By introducing elevation as a covariable, the interpolation accuracy of elevation-related meteorological factors can be improved significantly using AUNSPLINE. To test the accuracy of the results of the two methods, we used a cross-validation method to test the interpolation results and mainly investigated three parameters: mean absolute error (MAE), mean relative error (MRE) and root mean square error (RMSE).

In the validation method, points were selected three times (groups 1, 2 and 3 in Figure 2) for cross-validation. Fifteen sample points were randomly selected each time from 176 samples as verification points, and the other points were used for interpolation. The interpolation results for 15 sample points were extracted as predicted values, and relevant data for 45 verification points were obtained in the end. The accuracy of the two interpolation results was compared by calculating the three error parameters between the predicted value and the actual value of the 45 verification points. Meteorological data from June 1995 were used as the validation data. The analysis of the error results showed that the accuracy of AUNSPLINE is higher than that of the kriging method for the temperature interpolation (shown as Table 1). In this paper, the AUNSPLINE interpolation method was used for the average temperature, average minimum temperature, and average maximum temperature, and the kriging interpolation method was used for precipitation, sunshine percentage, and relative humidity.

\subsection{3 | Vegetation Type}

The vegetation type data used were the 1:100,000 spatial distribution data on vegetation types in China (grid data with 1 kilometer spatial resolution), which were provided by the Resource and Environment Data Cloud Platform(http://www.resdc.cn/). This data set reflects the actual distribution of more than 2000 dominant plant species as well as the major crops and cash crops in China and is the authoritative data set for vegetation type coverage in China.

\section{3 | Methods}

First, based on the vegetation type data with a higher spatial resolution, we obtained pure pixels of NDVI data, in which homogeneous vegetation exists. Then, we divided the research area into ecosystem-dependent subregions. We tested the variation trend in the NDVI time-series data with Mann-Kendall and Sen's slope estimator. These two methods are nonparametric methods that require only that the data be independent, regardless of whether the data are normally distributed (Gocic \& Trajkovic, 2013). Then, the lag correlation coefficient method was used to calculate the lag time of the vegetation response to the climate factors. Finally, stepwise regression was used to determine the factors influencing vegetation change.

\subsection{1 | Ecosystem-dependent subregions}

The vegetation type data were the basis of the regional classification in this study. The study area was divided into subregions according to the 1:100,000 vegetation data set of China. GIMMS NDVI3g data have a coarse resolution of approximately 8 kilometers. To a large extent, NDVI pixels are mixed and include a variety of land types or vegetation types. Therefore, we selected pure pixels as the study area to reduce the errors resulting from mixed pixels that contain a variety of ground object information. To select these pure pixels, NDVI data and vegetation raster data with higher resolution were raster-overlaid, and only those pixels with homogeneous vegetation were considered as the study area. In this way, we selected 10 dominant vegetation types on the Tibetan Plateau (Figure 3 and Table 2), and any other vegetation occupying smaller areas was ignored. 


\subsection{2 | Mann-Kendall and Sen's slope estimator}

To determine the change trends in the time-series vegetation activity, Theil-Sen median trend analysis was adopted. The method is a robust nonparametric statistical trend calculation method, and the formula is:

$\beta=\operatorname{median}\left(\frac{\mathrm{NDV}_{j}-\mathrm{NDV}_{i}}{j-i}\right)(1)$

Where $N D V I_{i}$ and $N D V I_{j}$ are the NDVI in years $i$ and $j(1985[?] i, j[?] 2015)$. When $\beta$ i 0 , it indicates that the NDVI increased during this period. When $\beta$ i0, it indicates that the NDVI decreased during this period.

The Mann-Kendall test is a relatively common time series trend test method that has been widely used in meteorology and hydrology (Yue et al., 2002). It is a nonparametric test method. The test formulas are listed below:

$$
\begin{aligned}
& Q=\sum_{j=1}^{n-1} \sum_{j=i+1}^{n} \operatorname{sign}\left(x_{j}-x_{i}\right)(2) \\
& \operatorname{sign}(s)=\{ \\
& 1 \quad a m p ; s>0 \\
& 0 \quad a m p ; s=0 \quad(3) \\
& -1 \quad a m p ; s<0 \\
& Z=\{ \\
& \frac{Q-1}{\sqrt{\operatorname{Var}(Q)}} \quad a m p ; Q>0 \\
& \begin{array}{cl}
0 & a m p ; Q=0 \quad(4) \\
\frac{Q-1}{\sqrt{\operatorname{Var}(Q)}} & a m p ; Q<0
\end{array}
\end{aligned}
$$

where $\mathrm{Q}$ is the test statistic, $\mathrm{Z}$ is the standardized test statistic, $x_{i}$ and $x_{j}$ are time series data; $\mathrm{n}$ is the number of samples. When $n$ [?]8, the results $\mathrm{Q}$ approximately follow a normal distribution. Its mean and variance are computed using Equations (5) and (6).

$E(Q)=0(5)$

$\operatorname{Var}(Q)=\frac{n(n-1)(2 n-5)}{18}(6)$

After normalization, $\mathrm{Z}$ follows a standard normal distribution. $|\mathrm{Z}|[?] 1.28,1.64$, and 2.32 indicate the confidence level of the calculation is more than $90 \%, 95 \%$ and $99 \%$, respectively.

\subsection{3 | Lag correlation coefficient}

Based on the understanding that the impact of climate change on vegetation occurs with a certain time lag, we adopted the lag correlation coefficient method to determine the lag period for the impact of climate factors on vegetation. Using this method, we calculated the correlation coefficient between NDVI and each climate factor in the current month as well as each climate factor in the previous 1-4 months. When the correlation coefficient reaches the maximum, the correlation between the vegetation NDVI and the climate factor is the strongest, which means that the vegetation activity had the strongest response to the climate factor in that month. And the lag time was recorded. The lag correlation coefficient is computed using Equation (7).

$R_{m}=\max \left\{R_{0}, R_{1}, R_{2}, \ldots, R_{n}\right\}$

Where $R_{n}$ is the lag correlation coefficient; $R_{1}, R_{2}, \ldots$, and $R_{n}$ are the current month, the month before the current month, the month two months before the current month, ..., and the month $n$ months before the current month, respectively; and $\mathrm{m}$ is the lag time. 


\subsubsection{Stepwise regression}

Stepwise regression is a method of fitting regression models where variables are considered one at a time for addition to or subtraction from the set of explanatory variables based on some criterion. This regression method can eliminate strong correlations between variables to some extent and increase the accuracy of the model. Whether the variable is added to the equation is determined by a sequence of F-tests . In each step, we considered the maximum value in the sequence of F-tests, and if the value passed the significance test of 0.01 , the corresponding variable was added to the regression equation.

\section{3 | RESULTS}

\subsection{The variation trends and spatial distribution characteristics of NDVI on the Tibetan Plateau}

The annual variation in the average NDVI on the Tibetan Plateau showed the same change trend, with only a single peak characteristic across the 31 years (Figure 4). In each year, NDVI begins to rise from April and reaches a maximum value in the period between August and September, which is the stage of vegetation growth. Therefore, April to September was used as the key period in this study.

Mann-Kendall and Sen's slope estimator was used to analyze the NDVI variation trends of vegetation on the Tibetan Plateau. The change trend was divided into five levels: significant increase, slight increase, remaining stable, slight decrease, and significant decrease. A significant increase or decrease indicates that the change trend passes the significance level test at 0.01 , and a slight increase or decrease indicates that the change trend passes the significance level test at 0.05 . The change trend proportion of each type of vegetation is shown in Figure 5. The bars indicate the proportion of the area that demonstrated each change trend.

The change trends show significant differences among the different types of vegetation. The change trends of vegetation were dominated by increasing trends in alpine steppe, alpine desert, temperate desert steppe, alpine sparse vegetation, temperate desert and temperate steppe. These vegetation types are mainly distributed in the northwest area of the Tibetan Plateau. Among them, the increasing trend for vegetation activity in the Alpine Desert was the most obvious. The change trends for vegetation were also dominated by decreasing trends in alpine meadow, subalpine scrub, needleleaf forest, and broadleaf evergreen forest. These types of vegetation are mainly distributed in the southeastern area of the Tibetan Plateau, which is a relatively low-altitude area with sufficient water and hot climate conditions, and their NDVI values are at a higher level than in other regions (Figure 6). The NDVI of the broadleaf evergreen forest, which is distributed on the edge of the southeastern region of the Tibetan Plateau $\left(93^{\circ} \mathrm{E}, 28^{\circ} \mathrm{N}\right)$, shows a more obvious decreasing trend than other vegetation types in recent years.

Based on previous knowledge, we took the alpine desert and broadleaf evergreen forest as typical examples. We analyzed the relationship between the average monthly NDVI of each year for the two types of vegetation and the climate in recent years. The NDVI variation in the alpine desert showed a significant increasing trend, while that of the broadleaf evergreen forest showed a significant decreasing trend. We also compared these two types of vegetation with the alpine meadow, where the overall regional level of NDVI change trend presented a state of equilibrium.

As shown in Figure 7, there are significant differences in the variation trends of climate factors in different regions, and there are significant differences in the influence on vegetation due to the comprehensive effects of climate factors. The average temperature change rates in alpine desert, alpine meadow, and broadleaf evergreen forest regions were 0.059/year, 0.048/year and 0.021/year, respectively. There have also been differences in local temperature changes, and the warming rate of the broadleaf evergreen forest area is slower than that of other regions. This also indicates that the sensitivity to temperature change in different regions is different, and the temperature increase rate in the low-temperature region is faster than that in the 
high-temperature region. This finding can also be obtained from the change rates of the average minimum or maximum temperature: the change rates of the average maximum temperature of the three groups are 0.034 year, $0.0405 /$ year, and $0.055 /$ year, and the change rates of the average minimum temperature of the three groups are 0.093/year, 0.073/year, and 0.018/year, respectively. We can see that the average minimum temperature in the cold region is changing at a very fast rate.

In addition to temperature, climate factors such as precipitation, relative humidity and monthly sunshine percentage also play an important role in vegetation growth. The precipitation change rates in the three regions are $0.102 \mathrm{~mm} /$ year, $0.143 \mathrm{~mm} /$ year and $-0.427 \mathrm{~mm} /$ year, respectively. The change in precipitation in the alpine desert region and in the alpine meadow region shows an increasing trend, while the change in precipitation in the broadleaf evergreen forest region shows a significant decreasing trend. The variation trend in the monthly sunshine percentage is $0.0339 \% /$ year, $-0.1089 \% /$ year and $-0.1163 \%$ /year, respectively, which indicates an overall downward trend. This finding indicates that the sunshine percentage during the growing season on the Tibetan Plateau has decreased in recent years. However, in the broadleaf evergreen forest zone, the decrease in sunshine percentage did not correspond to an increase in precipitation. The relative humidity of this region showed a significant decreasing trend $(-0.2144 \% /$ year $)$, indicating that the climate is becoming drier.

The variation trends in NDVI for the three types of vegetation are $0.000387 /$ year, $-0.0001 /$ year and $0.001406 /$ year, respectively. The vegetation activity of the alpine desert showed a significant increasing trend. The vegetation activity of the alpine meadow showed a slight declining trend. The vegetation activity of the broadleaf evergreen forest showed a significant declining trend. Although the regional air temperature increased significantly, the percentage of monthly sunshine in the alpine meadow region showed a more significant decreasing trend. Because the influence of climate factors on vegetation activity is the result of the combined action of several factors, the main factor limiting vegetation growth in this region may be the decrease in sunshine. Under further consideration, the NDVI value in the alpine meadow is at a higher level, and reduced light can effectively limit plant photosynthesis, thereby affecting vegetation activity.

As shown in Figure 6, four kinds of vegetation showed high NDVI values on the Tibetan Plateau, namely, in order of NDVI value: broadleaf evergreen forest, needleleaf forest, subalpine scrub, and alpine meadow. Their vegetation activities all showed a decreasing trend, and the decrease rates were, in order, broadleaf evergreen forest, needleleaf forest, subalpine scrub, and alpine meadow. The higher the NDVI value of the vegetation was, the faster the rate of NDVI reduction was which to some extent indicates that the reduction of sunlight affects the growth of these vegetation types. The other vegetation types with lower NDVI values showed increasing trends in each year. Under saturated sunshine time conditions, the increase in temperature has a more significant effect on these types of vegetation than on the previous four vegetation types.

\subsection{Correlation analysis of vegetation activity between different vegetation types and climatic factors}

The lag effect in the response of vegetation activity to climate factors has been demonstrated in many studies. According to the results of this study, the response of vegetation to various climate factors is significantly different in different vegetation types and vegetative growth stages.

On the whole, the response of vegetation activity to temperature is more significant than that to other factors, and the lag period varies greatly due to the different growth stages and vegetation types, namely, alpine meadow, alpine desert, temperate desert steppe, alpine sparse vegetation and temperate desert. The hysteresis correlation coefficient indicates that the lag in the response of vegetation activity to the average temperature and average maximum temperature is not obvious, while the lag in the response of vegetation activity to the average minimum temperature is 1 or 2 months (Figure 8).

The vegetation activity in the alpine steppe, alpine desert, temperate desert steppe, alpine sparse vegetation, temperate desert and temperate steppe shows a more significant response to precipitation than to other climate factors. Desert vegetation is the most sensitive to precipitation, followed by grassland vegetation, and finally shrub and tree vegetation. For most types of vegetation, there is little correlation between vegetation activity and precipitation at the start of the growing season. The correlation between vegetation 
activity and precipitation tends to show a single peak during the growing season. The correlation increases gradually and reaches a peak in July or August and then decreases gradually, which is related to the change in the water utilization rate of vegetation. In particular, the correlation between the vegetation activity of the temperate desert and precipitation gradually increased during the whole growing season. Therefore, precipitation may be the main factor affecting the end of the growing season, and it is also the limiting factor for the whole growing season of this type of vegetation. In terms of lag, the influence of precipitation on vegetation activity generally occurs with a lag period of 1 or 2 months. The correlation coefficients showed that the precipitation in May and June had the greatest impact on the growth activity of the alpine steppe, alpine sparse vegetation, and temperate desert vegetation types, and the precipitation in June and July had a greater impact on the growth activity of the alpine desert, temperate desert and temperate steppe.

Subalpine scrub, needle leaf forest and broadleaf evergreen forest were most sensitive to the percentage of sunlight and did not demonstrate a lag effect. Compared with those of temperature and precipitation, the effect of sunshine on vegetation growth for these vegetation types was more significant.

\subsection{Interpretation of vegetation activity with climatic factors}

We focused on the correlation between vegetation activity at the start of the season (SOS) and the end of the season (EOS) and climate factors. Previous studies have shown that approximately 13-19\% of global regions have experienced changes in growth season length, and approximately $30 \%$ of the changes occurred in the northern alpine biome in the northern hemisphere (Garonna et al., 2016). Therefore, it is of great significance to study the main climatic factors that affect vegetation activity at the SOS and EOS when studying growing season change mechanisms on the Tibetan Plateau.

At the SOS, precipitation initially had no influence on vegetation growth (all regression coefficients were between -0.2 and 0.2 , as shown in Figure 9a). The initial growth period for most vegetation is greatly influenced by the sunshine percentage. Specifically, the average maximum temperature and average temperature had positive effects on the growth of the alpine desert, while the average minimum temperature had negative effects on its growth. Moreover, the temperate desert and alpine steppe were not affected by climate factors at the start of the growing season.

Many vegetation types at the EOS were influenced by a variety of climatic factors, as shown in Figure $9 \mathrm{~b}$. Precipitation had a strong influence on the growth of the temperate desert steppe, temperate steppe, temperate desert and needleleaf forest in September. Moreover, precipitation had the greatest influence on the growth of the temperate desert steppe at the end of the growing season, as increased precipitation may prolong the growing season of this vegetation. Specifically, we can also see that precipitation had a negative impact on the alpine meadow. The relative humidity had a negative impact on the temperate desert steppe and had strong positive influences on the alpine meadow, as shown in Figure 9b. Subalpine scrub and alpine steppe were not affected by climate factors at the end of the growing season. No climate factor had a significant influence on the growth of the alpine steppe at either the start or end of the growing season.

\section{4 | DISCUSSION}

\subsection{Change trends of climate factors and vegetation coverage on the Tibetan Plateau}

Based on the GIMMS NDVI3g data, the NDVI variation trend on the Tibetan Plateau in the last 31 years presents strong heterogeneity in different vegetation ecosystems (Figure 5), but the overall change trend is dominated by increases. However, due to drastic changes in the environment, large areas of grassland degradation had appeared on the Tibetan Plateau before the 1980s, and the alpine grassland and alpine marsh meadow vegetation in the Maduo and Tuotuo river areas had been degraded on a large scale (ZHANG et al. 2011). Considering that the vegetation activity in degraded grasslands will not be significantly increased 
with the improvement of climate conditions over a short period, this may also be the main reason that the vegetation activity of the alpine meadow and alpine grassland did not increase significantly. The GIMMS3g data underestimated the greening trend on the Tibetan Plateau ( $\mathrm{Li}$ et al., 2018) mainly because of the impacts of sensor shifts and degradation, especially at the break point of sensor shifts (Zhang et al., 2017; Detsch et al., 2016). According to the research results of Li et al. (2018), the GIMMS NDVI data from 2000 to 2006 showed an inconsistent trend with the SPOT-VGT data and MODIS data from the same period, showing a significant decrease in NDVI, especially on the western Tibetan Plateau. Therefore, the overall NDVI increase area on the Tibetan Plateau may be larger than that indicated by this paper.

Figure 6 shows that, on the Tibetan Plateau, the vegetation activity of the types of vegetation with a high NDVI value displays a declining trend; these types of vegetation have a larger demand for sunshine than others, and a decrease in radiance time results in a loss of vegetation activity. As shown in Figure 8, the percentage of monthly sunshine on the Tibetan Plateau is decreasing. You et al. (2009) also found that the mean annual sunshine duration showed a significant decrease from 1983 to 2005 at a rate of -65.1 hours/decade over the eastern and central Tibetan Plateau. Generally, sunshine duration is mainly influenced by cloud cover or aerosols, and an increase in cloud cover or in the aerosol concentration emitted by humans results in a decrease in the sunshine duration (Graham et al., 2003). The decrease in the annual and summer sunshine hours in Tibet may be related to the increase in atmospheric vapor pressure and precipitation (Du et al., 2007).

\section{2 | Lag in the vegetation activity response to precipitation}

Studies have confirmed that the influence of precipitation on vegetation shows a certain hysteresis. Rainfall is first converted to soil water before it can be absorbed by plants for transpiration, which is the driving force behind water and nutrient uptake by vegetation. The process by which precipitation is converted into water that is available for vegetation is related to the soil type, land cover, physiological characteristics of the vegetation, climate conditions and so on (Schwinning \& Sala, 2004). Due to the different soil types and topography, the soil water holding capacity is different in different areas. Some soils can retain water for a long time after rainfall, which has a lasting impact on vegetation growth. Here, Table 3 shows that for the alpine steppe, alpine meadow, alpine sparse vegetation and subalpine scrub, the field capacity increases in the same order as the six-monthly average lag time of the influence of precipitation on vegetation. In particular, although the soil there does not hold water for long periods, the precipitation effect has a 2.17-month lag time in the temperate desert, which indicates that in arid regions, the lag time may be longer than that in other regions. In addition, deep-rooted plants may have a longer "memory" for precipitation, according to Philippon et al., 2005.

\section{3 | Possible mechanisms of climate influences on vegetation}

Precipitation rarely affects vegetation activity at the SOS, as shown in Figure 8. According to the research of Yuan-He \& Shi-Long. (2006), in the low-temperature environment of the Tibetan Plateau, at the beginning of the growing season, precipitation can promote the growth of vegetation only after microorganisms regulate the $\mathrm{N}$ and $\mathrm{P}$ cycles. The activity of microorganisms is highly correlated with both the air temperature and soil temperature, which are related to radiation. This conclusion is a good explanation for why the rainfall and vegetation activity in the early stage of the growing season are hardly correlated.

In the needleleaf forest and broadleaf evergreen forest ecosystems, which are heat- and water-abundant regions, long-term radiation can provide photosynthetic energy for vegetation. Therefore, the vegetation activity is greatly influenced by the sunshine duration. The decrease in the sunshine duration is the main reason for the decrease in NDVI for these two types of vegetation. According to Graham et al. (2003), the changes in solar radiation caused by clouds and aerosols mainly affect the growth of plants by affecting the absorption of carbon dioxide by vegetation.

In September, the regression coefficient of the relationship of precipitation to the NDVI for alpine meadow vegetation was negative (Figure $9 \mathrm{~b}$ ). However, the average monthly precipitation in the alpine meadow region 
was $60-80 \mathrm{~mm}$. Vegetation activity no longer responds to precipitation when the precipitation amount exceeds a certain threshold (Martiny et al., 2006; DAVENPORT \& NICHOLSON, 1993). Therefore, precipitation may not significantly affect the vegetation activity in the alpine meadow. At the same time, the relative humidity has a significant positive effect on alpine meadow vegetation. In the past 31 years, the precipitation increased significantly, and the relative humidity decreased significantly (Figure 7). On the one hand, relative humidity affects the transpiration of vegetation and nutrient migration by influencing the atmospheric water potential. On the other hand, lower humidity can cause stomatal closure, which prevents carbon dioxide from being absorbed by the vegetation, thus reducing photosynthesis. Therefore, for alpine meadows, humidity may be the main climatic factor affecting this type of vegetation, and the reduction in humidity caused a slight decrease in alpine vegetation activity even though the temperature increased significantly.

\section{5 | CONCLUSION}

The interannual vegetation activity on the Tibetan Plateau shows an overall increasing trend, but there is strong spatial heterogeneity. The NDVI of the alpine desert increased the most significantly of all studied vegetation types. The NDVI values of four types of vegetation, namely, alpine meadow, subalpine scrub, needleleaf forest and broadleaf evergreen forest, showed a decreasing trend, but their NDVI values were typically larger than those of the other vegetation types.

The responses of vegetation to temperature, precipitation and relative humidity have certain lag periods. The alpine meadow, alpine desert, temperate desert steppe and temperate desert respond more significantly to temperature than to other climate factors, and the length of the lag period varies greatly in different vegetation ecosystems and growth stages. Desert vegetation is the most sensitive to precipitation, followed by grassland vegetation and finally shrubs. The response of vegetation activity to precipitation generally occurs with a lag period of 1 or 2 months. During the whole growing season, the correlation between vegetation activity and precipitation first increased to reach a peak and then decreased.

At the start of the growing season, temperature is the main climatic factor that affects the activity of most vegetation. After that, precipitation begins to have an effect on vegetation. The duration of sunshine has a relatively important impact on the vegetation activity in the alpine meadow, alpine sparse vegetation, subalpine scrub, needleleaf forest, and broadleaf evergreen forest. At the end of the growing season, many climatic influencing factors simultaneously affect vegetation activity.

This study mainly provided an overview of how different climate factors affect domain types of vegetation on the Tibetan Plateau. These findings will provide a better understanding of the climate change trends and contribute to the general knowledge of the drivers and mechanisms of ecosystem-dependent vegetation degradation on the Tibetan Plateau. For further study, high spatial and temporal resolution data are required for more accurate analyses of the lag effects and ecological mechanisms.

\section{Acknowledgments}

This research has been funded by grants from the funds for International Cooperation and Exchange of National Natural Science Foundation of China, No. 31761143018 and the National Key Research and Development Program of China, No. 2016YFC0501800/2016YFC0501801. In addition, the authors are very grateful for the China Meteorological Data Service Center (http://data.cma.cn/) for providing climate data and the Ecological Forecasting Lab at NASA Ames Research Center (https://ecocast.arc.nasa.gov/) for providing NDVI data, and the Resource and Environment Data Cloud Platform for providing vegetation data. The authors are also grateful to the anonymous reviewers and the editors for valuable comments and suggestions for improving the manuscript.

\section{Conflict of Interest Statement}

No potential conflict of interest was reported by the authors. 


\section{REFERENCES}

Xuefeng Cui, Hans-F. Graf. (2009). Recent land cover changes on the Tibetan Plateau: a review. Climatic Change, 94, 47-61.doi:10.1007/s10584-009-9556-8

Shilong Piao, Jingyun Fang, Wei Ji, Qinghua Guo, Jinhu Ke, Shu Tao. (2004). Variation in a satellitebased vegetation index in relation to climate in China. Journal of Vegetation Science,15, 219 - 226. doi:10.1658/1100-9233(2004)015[0219:VIASVI]2.0.CO;2

Guojin Pang, Xuejia Wang, Meixue Yang. (2017). Using the NDVI to identify variations in and responses of, vegetation to climate change on the Tibetan Plateau from 1982 to 2012. Quaternary International, 444, 87-96. doi:10.1016/j.quaint.2016.08.038

C. S. Potter, V. Brooks. (1998). Global analysis of empirical relations between annual climate and seasonality of NDVI. International Journal of Remote Sensing, 19, 2921-2948. doi:10.1080/014311698214352

Bing Guo, Yi Zhou, Shi-xin Wang, He-ping Tao. (2014). The relationship between normalized difference vegetation index (NDVI) and climate factors in the semiarid region: A case study in Yalu Tsangpo River basin of Qinghai-Tibet Plateau. Journal of Mountain Science, 11, 926-940. doi:10.1007/s11629-013-2902-3

V. Krishna Prasad, K. V. S. Badarinath, Anuradha Eaturu.(2008). Effects of precipitation temperature and topographic parameters on evergreen vegetation greenery in the Western Ghats, India. International Journal of Climatology, 28, 1807-1819. doi:10.1002/joc.1662

Ma Mingguo, Frank Veroustraete. (2004). INTERANNUAL CHANGE TREND OF NDVI FROM 1981 TO 2001 IN THE HEIHE RIVER BASIN, CHINA. Proceedings of the Second International VEGETATION User Conference, 1, 231 - 237.

T FARRAR, S NICHOLSON, A LARE. (1994). The influence of soil type on the relationships between NDVI rainfall and soil moisture in semiarid Botswana. II. NDVI response to soil oisture. Remote Sensing of Environment, 50, 121-133. doi:10.1016/0034-4257(94)90039-6

Michael A. White, Peter E. Thornton, Steven W. Running. (1997). A continental phenology model for monitoring vegetation responses to interannual climatic variability. Global Biogeochemical Cycles, 11, 217234. doi:10.1016/0034-4257(94)90039-6

WANG Li, YU Haiying, Zhi-Qiang Zhang, Yunjia Xu, Zexing Tao, Juha Alatalo, Junhu Dai. (2018). Responses of aboveground biomass of alpine grasslands to climate changes on the Qinghai-Tibet Plateau. Journal of Geographical Sciences, 28, 1953-1964. doi:10.1007/s11442-019-1573-y

Hongshuo Wang, Desheng Liu, Hui Lin, Alvaro Montenegro, Xiaolin Zhu. (2014). NDVI and vegetation phenology dynamics under the influence of sunshine duration on the Tibetan plateau. International Journal of Climatology, 35, 687-698. doi:10.1002/joc.4013

Shengpan Lin, Nathan J. Moore, Joseph P. Messina, Jiaping Wu. (2013). Evaluation of MODIS surrogates for meteorological humidity data in east Africa. International Journal of Remote Sensing 34, 4669-4679. doi:10.1080/01431161.2013.781288

F.I. Woodward, I.F. McKee. (1991). Vegetation and climate. Environment International, 17, 535-546. doi:10.1016/0160-4120(91)90166-n

M.V.K. Sivakumar. (1988). Predicting rainy season potential from the onset of rains in Southern Sahelian and Sudanian climatic zones of West Africa. Agricultural and Forest Meteorology, 42, 295-305. doi:10.1080/01431169308954042

M. L. DAVENPORT, S. E. NICHOLSON. (1993). On the relation between rainfall and the Normalized Difference Vegetation Index for diverse vegetation types in East Africa. International Journal of Remote Sensing, 14, 2369-2389. doi:10.1080/01431169308954042 
Valerio Capecchi, Alfonso Crisci, Genesio Lorenzo, Fabio Maselli, Patrizio Vignaroli. (2008). Analysis of NDVI trends and their climatic origin in the Sahel 19862000. Geocarto International, 23, 297-31. doi:10.1080/10106040801950492

Nathalie Philippon, Eric Mougin, Lionel Jarlan, Pierre-Louis Frison. (2005). Analysis of the linkages between rainfall and land surface conditions in the West African monsoon through CMAP ERS-WSC and NOAAAVHRR data. Journal of Geophysical Research, 110. doi:10.1029/2005jd006394

N. Martiny, Y. Richard, P. Camberlin. (2005). Interannual persistence effects in vegetation dynamics of semi-arid Africa. Geophysical Research Letters, 32. doi:10.1029/2005gl024634

Shilong Piao. (2003). Interannual variations of monthly and seasonal normalized difference vegetation index (NDVI) in China from 1982 to 1999. Journal of Geophysical Research, 108. doi:10.1029/2002jd002848

Zhaofei Wen, Shengjun Wu, Jilong Chen, Mingquan Lu. (2017). NDVI indicated long-term interannual changes in vegetation activities and their responses to climatic and anthropogenic factors in the Three Gorges Reservoir Region China. Science of The Total Environment, 574, 947-959. doi:10.1016/j.scitotenv.2016.09.049

Nathalie Pettorelli, Jon Olav Vik, Atle Mysterud, Jean-Michel Gaillard, Compton J. Tucker, Nils Chr. Stenseth. (2005). Using the satellite-derived NDVI to assess ecological responses to environmental change. Trends in Ecology \& Evolution, 20, 503-510. doi:10.1016/j.tree.2005.05.011

BRENT N. HOLBEN. (1986). Characteristics of maximum-value composite images from temporal AVHRR data. International Journal of Remote Sensing, 7, 1417-1434. doi:10.1080/01431168608948945

Milan Gocic, Slavisa Trajkovic. (2013). Analysis of changes in meteorological variables using MannKendall and Sens slope estimator statistical tests in Serbia. Global and Planetary Change, 100, 172-182. doi:10.1016/j.gloplacha.2012.10.014

Sheng Yue, Paul Pilon, George Cavadias. (2002). Power of the MannKendall and Spearmans rho tests for detecting monotonic trends in hydrological series. Journal of Hydrology, 259, 254-271. doi:10.1016/s00221694(01)00594-7

Irene Garonna, Rogier de Jong, Michael E. Schaepman. (2016). Variability and evolution of global land surface phenology over the past three decades (1982-2012). Global Change Biology, 22, 1456-1468. doi:10.1111/gcb.13168

Lanhui Li, Yili Zhang, Linshan Liu, Jianshuang Wu, Zhaofeng Wang, Shicheng Li, Huamin Zhang, Jiaxing Zu, Mingjun Ding, Basanta Paudel. (2018). Spatiotemporal Patterns of Vegetation Greenness Change and Associated Climatic and Anthropogenic Drivers on the Tibetan Plateau during 20002015. Remote Sensing, 10, 1525. doi:10.3390/rs10101525

Yulong Zhang, Conghe Song, Lawrence E. Band, Ge Sun, Junxiang Li. (2017). Reanalysis of global terrestrial vegetation trends from MODIS products: Browning or greening?. Remote Sensing of Environment 191, 145155. doi:10.1016/j.rse.2016.12.018

Florian Detsch, Insa Otte, Tim Appelhans, Thomas Nauss. (2016). A Comparative Study of Cross-Product NDVI Dynamics in the Kilimanjaro RegionA Matter of Sensor Degradation Calibration, and Significance. Remote Sensing 8, 159. doi:10.3390/rs8020159

Lanhui Li, Yili Zhang, Linshan Liu, Jianshuang Wu, Shicheng Li, Haiyan Zhang, Binghua Zhang, Mingjun Ding, Zhaofeng Wang, Basanta Paudel. (2018). Current challenges in distinguishing climatic and anthropogenic contributions to alpine grassland variation on the Tibetan Plateau. Ecology and Evolution, 8, 5949-5963. doi:10.1002/ece3.4099

Qinglong You, Shichang Kang, Wolfgang-Albert Flugel, Arturo Sanchez-Lorenzo, Yuping Yan, Jie Huang, Javier Martin-Vide. (2009). From brightening to dimming in sunshine duration over the eastern and central 
Tibetan Plateau (19612005). Theoretical and Applied Climatology, 101, 445-457. doi: 10.1007/s00704-0090231-9

E. A. Graham, S. S. Mulkey, K. Kitajima, N. G. Phillips, S. J. Wright. (2003). Cloud cover limits net CO2 uptake and growth of a rainforest tree during tropical rainy seasons. Proceedings of the National Academy of Sciences, 100, 572-576. doi:10.1073/pnas.0133045100

J. Du, D. Bian, Jiehui hu, J. Liao, M. Zhou. (2007). Climatic change of sunshine duration and its influencing factors over Tibet during the last 35 years. Acta Geographica Sinica, 62, 492-500. doi:10.3321/j.issn:03755444.2007 .05 .005

Susanne Schwinning, Osvaldo E. Sala. (2004). Hierarchy of responses to resource pulses in arid and semi-arid ecosystems. Oecologia, 141, 211-220. doi:10.1007/s00442-004-1520-8

YANG Yuan-He, PIAO Shi-Long. (2006). VARIATIONS IN GRASSLAND VEGETATION COVER IN RELATION TO CLIMATIC FACTORS ON THE TIBETAN PLATEAU. Chinese Journal of Plant Ecology, 30, 1-8. doi:10.17521/cjpe.2006.0001

Nadege Martiny, Pierre Camberlin, Yves Richard, Nathalie Philippon. (2006). Compared regimes of NDVI and Rainfall in semi-arid regions of Africa. International Journal of Remote Sensing - INT J REMOTE SENS, 27, 5201-5223. doi:10.1080/01431160600567787

Lei Ji, Albert J. Peters. (2003). Assessing vegetation response to drought in the northern Great Plains using vegetation and drought indices. Remote Sensing of Environment, 87, 85-98. doi:10.1016/s00344257(03)00174-3

Shilong Piao, Jingyun Fang, Wei Ji, Qinghua Guo, Jinhu Ke. (2004). Variation in a satellite-based vegetation index in relation to climate in China. Journal of Vegetation Science, 15, 219. doi:10.1658/11009233(2004)015[0219:VIASVI]2.0.CO;2

Yanfei Wang, Zhihua Sun, Hailong Hu, Shengyu Jing, Bing Zhao, Weiqing Xu, Chun Zhao, John R. Lombardi. (2006). Raman scattering study of molecules adsorbed on ZnS nanocrystals. Journal of Raman Spectroscopy 38, 34-38. doi:10.1002/jrs.1570

YANG Yuan-He, and PIAO Shi-Long. (2006). VARIATIONS IN GRASSLAND VEGETATION COVER IN RELATION TO CLIMATIC FACTORS ON THE TIBETAN PLATEAU. Chinese Journal of Plant Ecology 30, 1-8. doi:10.17521/cjpe.2006.0001

\section{Hosted file}

Tables.doc available at https://authorea.com/users/299160/articles/455771-ecosystemdependent-responses-of-vegetation-coverage-on-the-tibetan-plateau-to-climate-factorsand-their-lag-periods

\section{Hosted file}

Figure_legends.doc available at https://authorea.com/users/299160/articles/455771-ecosystemdependent-responses-of-vegetation-coverage-on-the-tibetan-plateau-to-climate-factorsand-their-lag-periods 

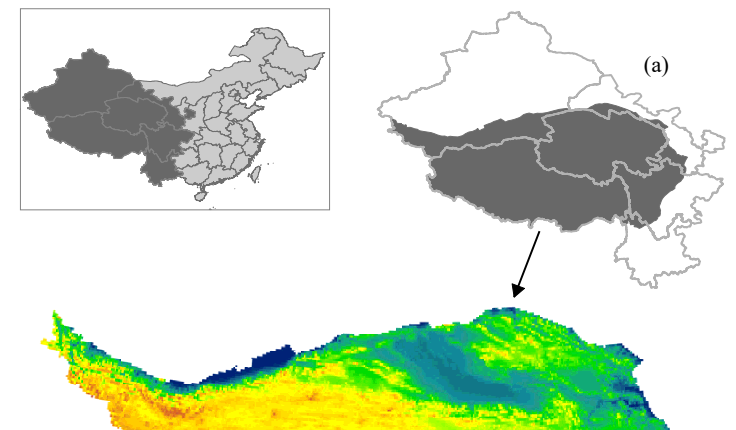

(b)

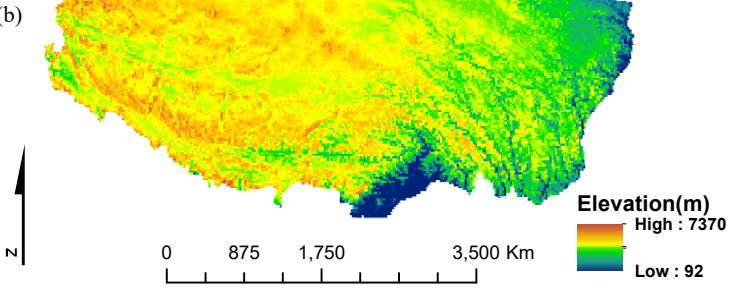




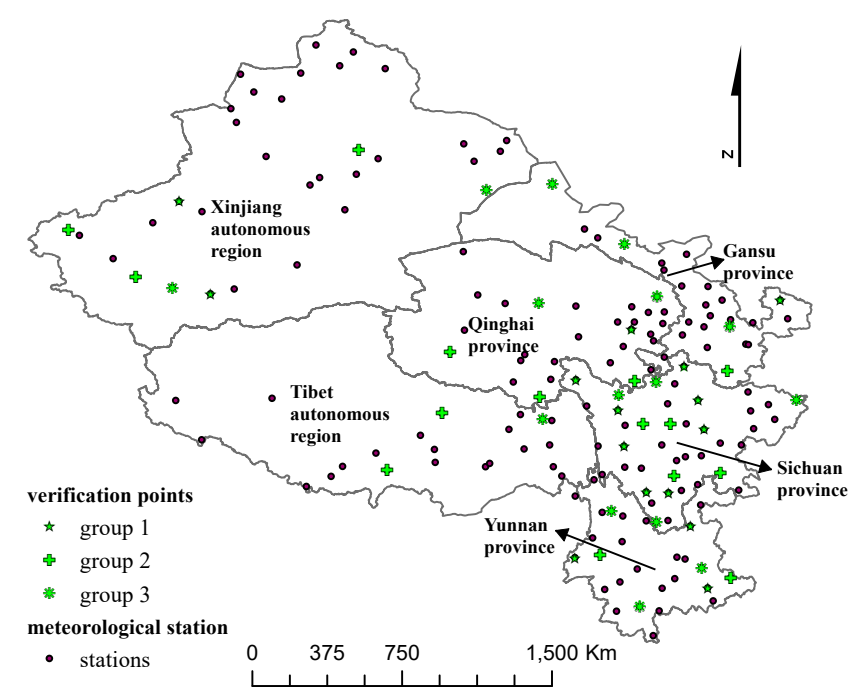




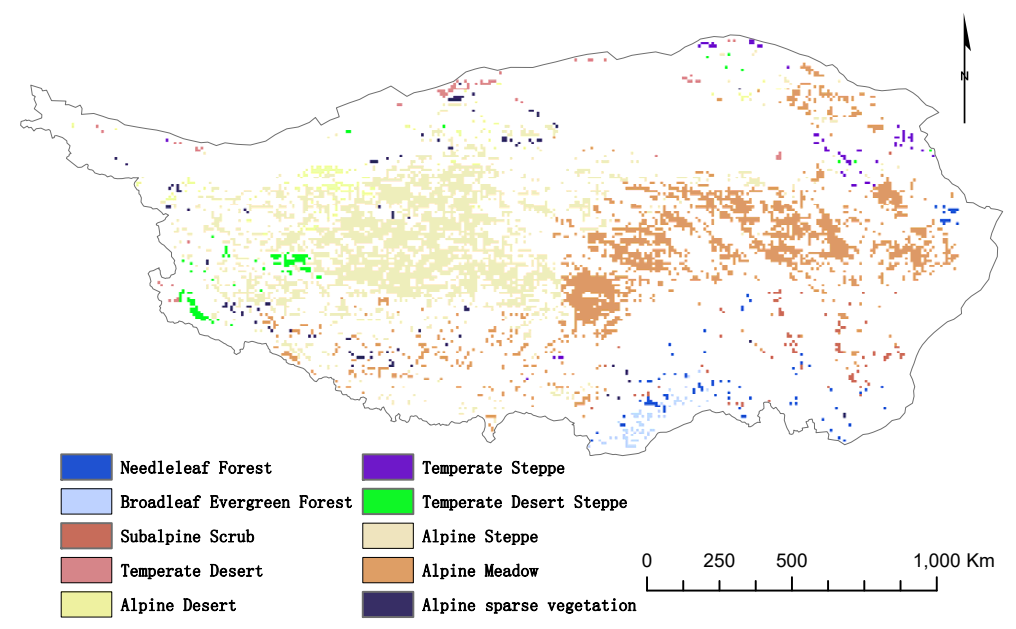



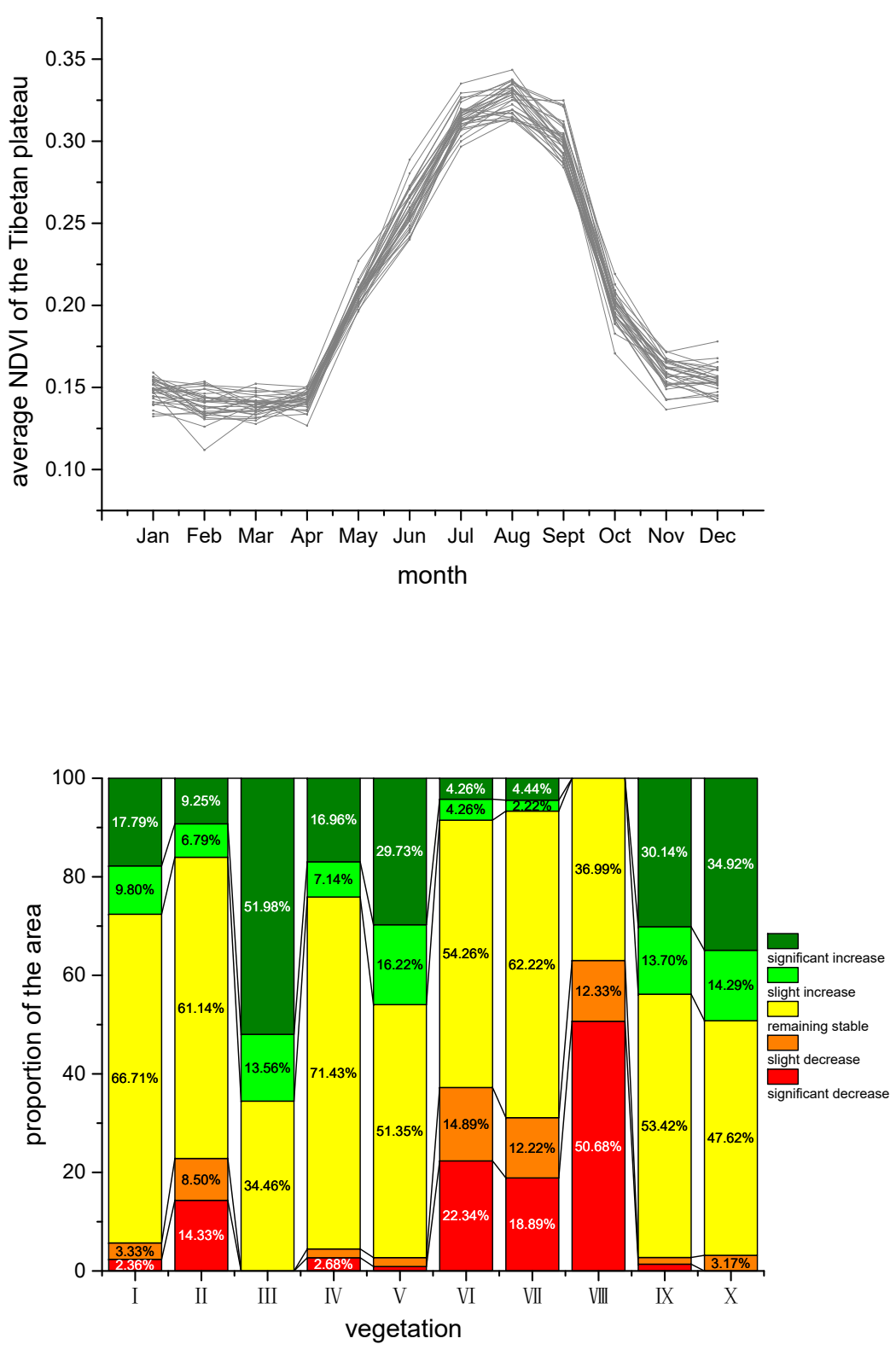


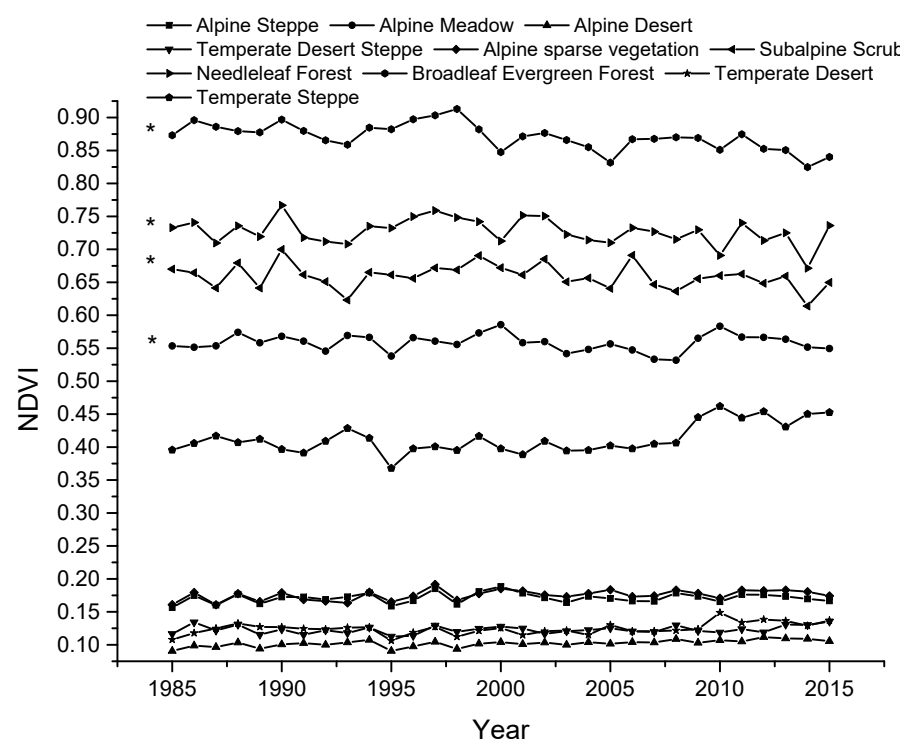


(a)

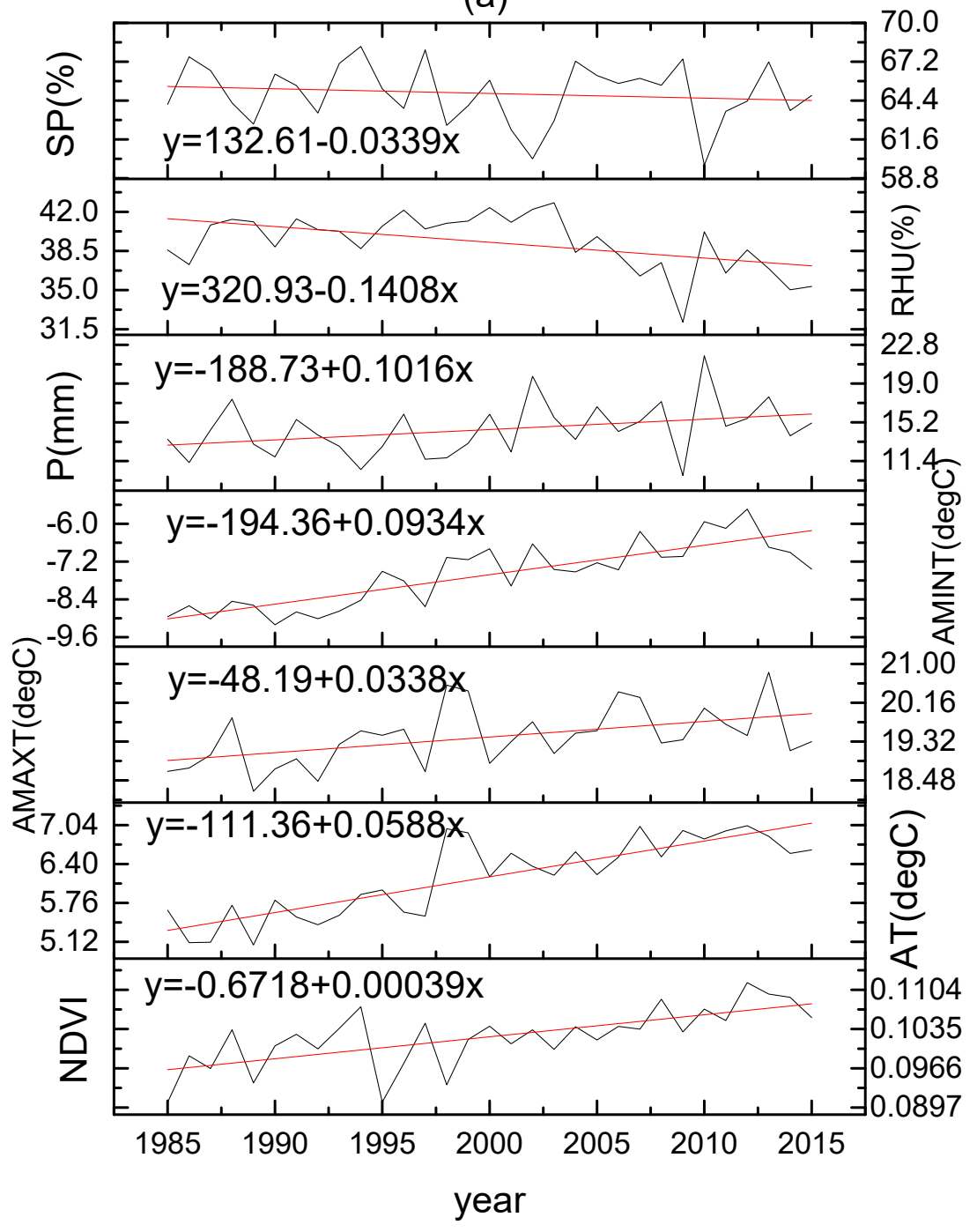



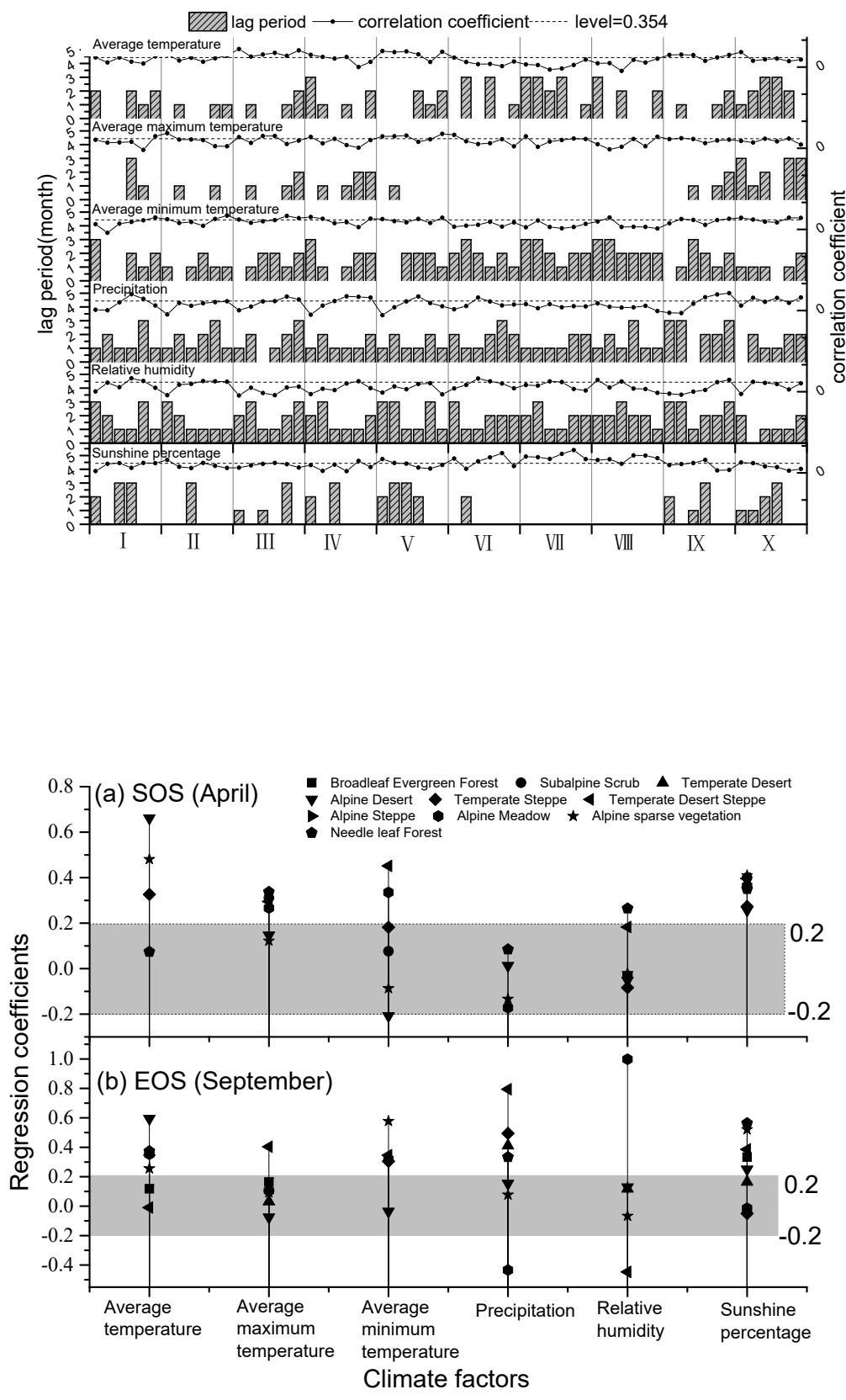